\title{
Range Extension of the Regulus Seastar Pentaceraster regulus (Müller \& Troschel, 1842) (Echinodermata: Asteroidea: Oreasteridae): Evidence of Tropicalization of the East Australian Coast
}

\author{
Stephen J. Keable ${ }^{1}$ iD and Christopher L. MaH $^{2}$ iD \\ ${ }^{1}$ Marine Invertebrates, Australian Museum Research Institute, \\ Australian Museum, 1 William Street, Sydney NSW 2010, Australia \\ ${ }^{2}$ Department of Invertebrate Zoology NMNH, \\ Smithsonian Institution, United States of America
}

\begin{abstract}
The seastar Pentaceraster regulus (Müller \& Troschel, 1842) is documented from the coastal estuary of Wallis Lake, New South Wales, Australia, c. $600 \mathrm{~km}$ from the nearest previous records at Lord Howe Island, an offshore area known to receive a tropical influence from the southern flowing East Australian Current, and between 640 to $800 \mathrm{~km}$ south of earlier published records from mainland areas to the north in Queensland. Historical data combined with contemporary observations provide evidence that this is a recent range extension and may be a further example of tropicalization of the south eastern Australian coastal waters. Records from Wallis Lake span a twelve year period and the most recent observations in 2020 indicate it is abundant, and there is considerable difference between the smallest and largest specimens present, suggesting a population that completes most or all of the life cycle is established in the estuary. Given the impacts range shifted species and other echinoderms are known to have in influencing ecosystem dynamics, it is suggested that further study of this seastar is prudent to determine what impacts it may have in the newly colonized area.
\end{abstract}

\section{Introduction}

Continuous tropical-temperate coastlines that are strongly influenced by western boundary currents, including eastern Australia, are potential hotspots for biological change as organisms respond to warming of these coastal waters (Verges et al., 2014). Such biological change includes poleward range expansions of numerous species (Flagor \& Bourdeau, 2018). These range expansions may involve shifts from tropical locations to areas previously considered temperate, a process that has been termed tropicalization (Verges et al., 2014). New interactions when range-shifted species arrive can cascade through communities and have the potential for significant socio-economic impacts, particularly if they involve the appearance of keystone or foundation species (Verges et al., 2014). A significant example of this is the echinoid echinoderm Centrostephanus rodgersii which has relatively recently extended its range in southeastern Australia to Tasmania where it not only impacts on the local ecosystem, by overgrazing kelp beds, but affects associated fisheries for abalone and southern rock lobster that depend on the kelp bed habitat (Byrne \& Andrew, 2013; Ling \& Keane, 2018). Therefore, it is important to document similar instances when they are observed so that they can be further investigated and mitigation procedures can be implemented if deemed necessary. 

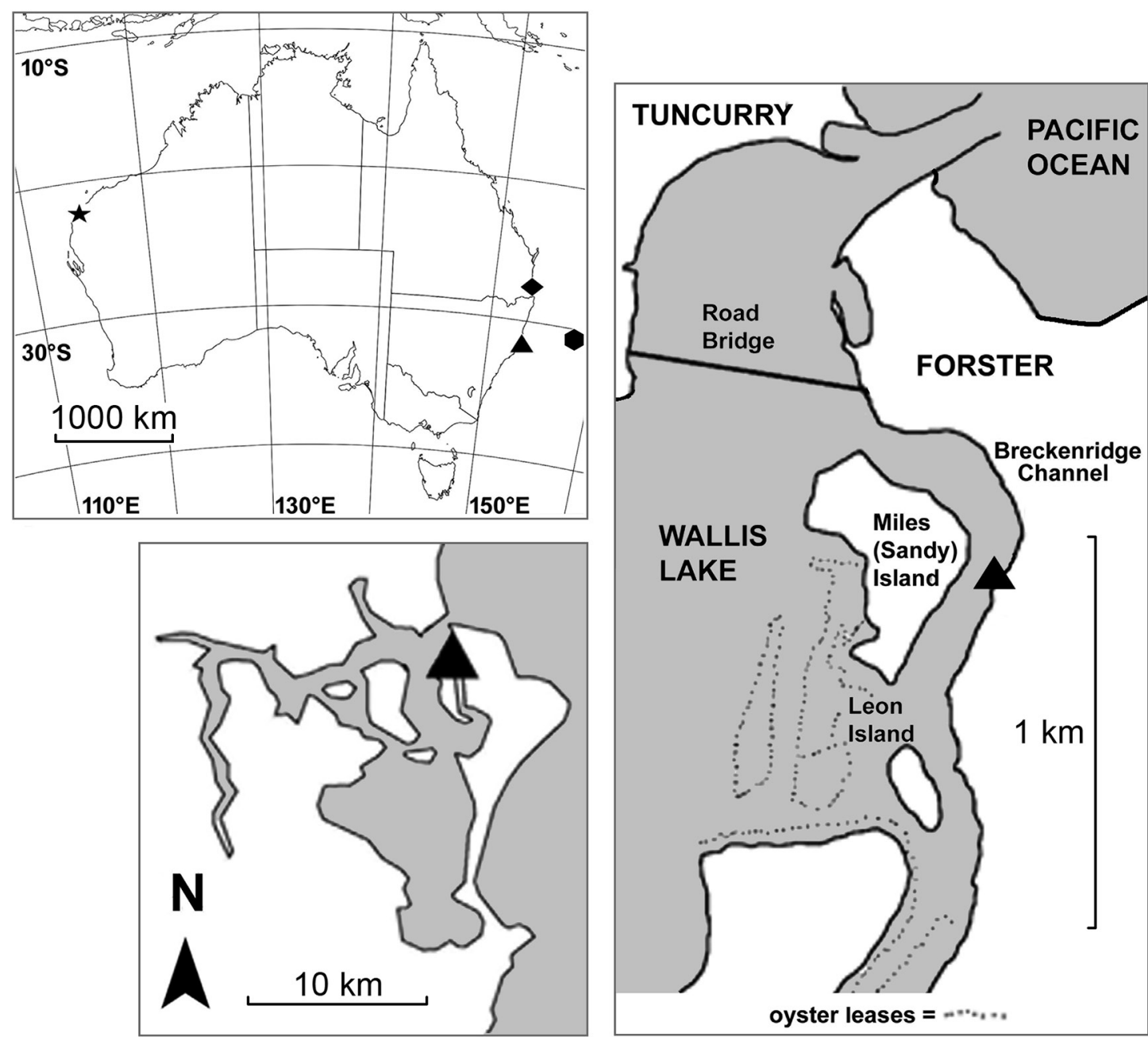

Figure 1. Location of previously documented southern records of Pentaceraster regulus and those recorded here, and other localities referred to in the text. Top left, approximate locations, $\star=$ Ningaloo Reef, Western Australia; $\boldsymbol{\nabla}=$ Stradbroke Island, Queensland; $=$ Lord Howe Island; $\boldsymbol{\Delta}=$ Wallis Lake, New South Wales.

Here we report the presence of the asteroid echinoderm Pentaceraster regulus (Müller \& Troschel, 1842) on the Australian eastern seaboard c. $800 \mathrm{~km}$ further south than previous published mainland records and $600 \mathrm{~km}$ from the nearest offshore record at Lord Howe Island. Additionally, we discuss evidence that this is an example of another poleward range-expansion and a further indication of the tropicalization of southeastern Australian coastal waters.

\section{Materials and methods}

The specimens examined were obtained from within Wallis Lake, a tidal estuary on the Mid North Coast of New South Wales, Australia (Great Lakes Council, 2014; Fig. 1). They are preserved in ethanol in the collections of the Australian Museum, Sydney. Morphological terms and measurements follow those of Marsh \& Fromont (2020). Abbreviations are: $A M$, Australian Museum, Sydney; $R$, major radius (mouth to arm-tip).

\section{Results and discussion}

Oreasteridae Fisher, 1908

Pentaceraster Döderlein, 1916

\section{Pentaceraster regulus \\ (Müller \& Troschel, 1842)}

Restricted synonymy of primary references only, following ABRS (2021).

Oreaster regulus Müller \& Troschel, 1842: 51.

Oreaster australis Lütken, 1871: 252, 263.

Pentaceraster odhneri Döderlein, 1926: 8, pl. 2(1-1a).

Figs 2-5, 7

\section{Material examined}

AM J.24502, 1 specimen (R 98 mm), Forster Marina, Cape Hawke Harbour, New South Wales, Australia, 32¹1'30"S $152^{\circ} 30^{\prime} 40^{\prime \prime E}$, collected A. Bowd, 14 Jan. 2008, donated M. Koukoulas, hand collected on snorkel, sandy substrate with Zostera, 5-7 m; AM J.24503, 1 specimen (R 118 mm), same data as AM J.24502; AM J.27402, 5 specimens (R 65, 85, 92, 97, $114 \mathrm{~mm}$ ), Wallis Lake, New South Wales, Australia, $32^{\circ} 11^{\prime} 4^{\prime \prime S} 152^{\circ} 30^{\prime} 41^{\prime \prime E}$, collected and donated S. Patterson, 

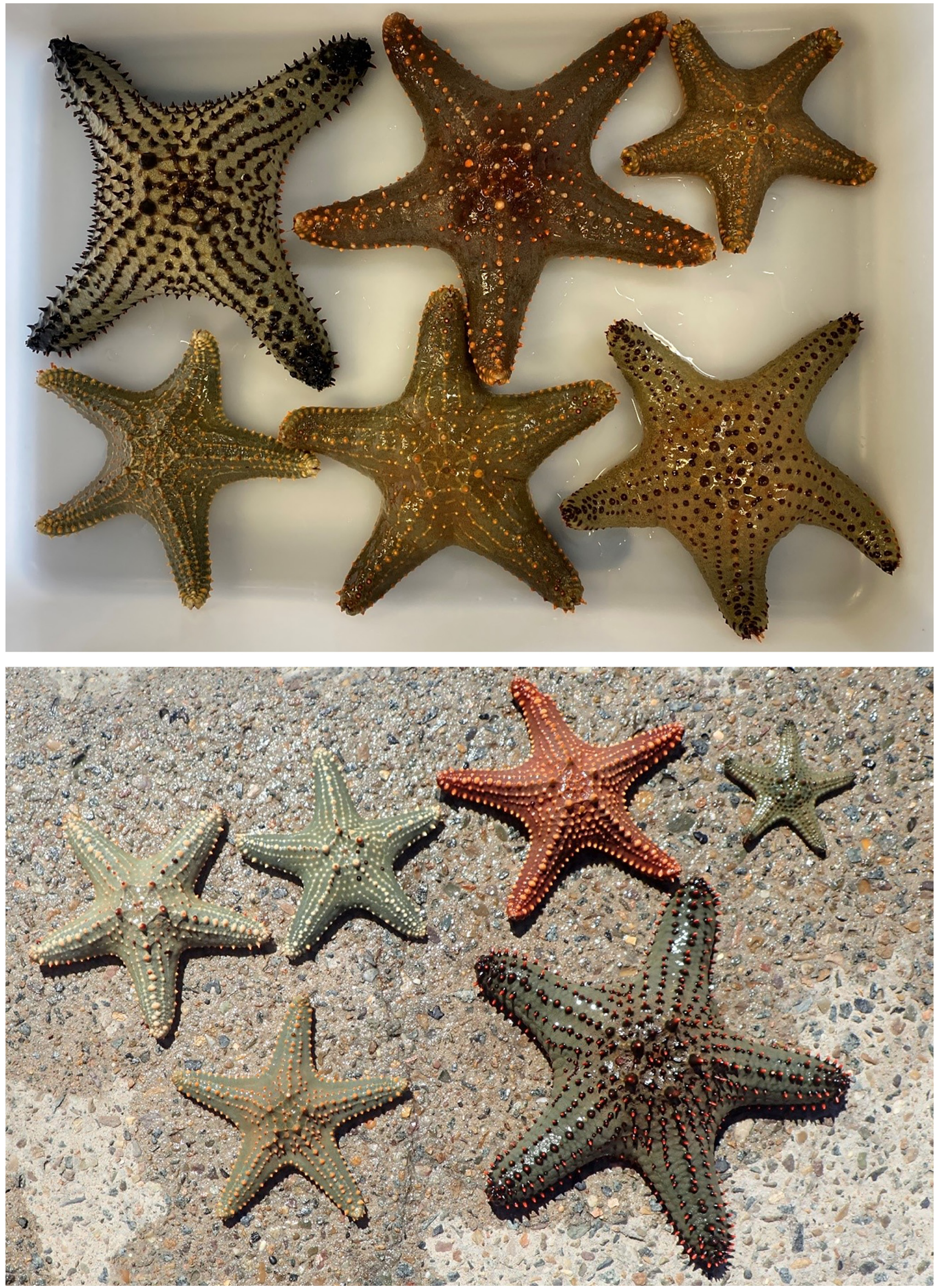

Figure 2. Live specimens of Pentaceraster regulus from Wallis Lake, abactinal surface. Top image, upper left specimen AM J.27403, remainder AM J.27402. Bottom image AM J.27404. 

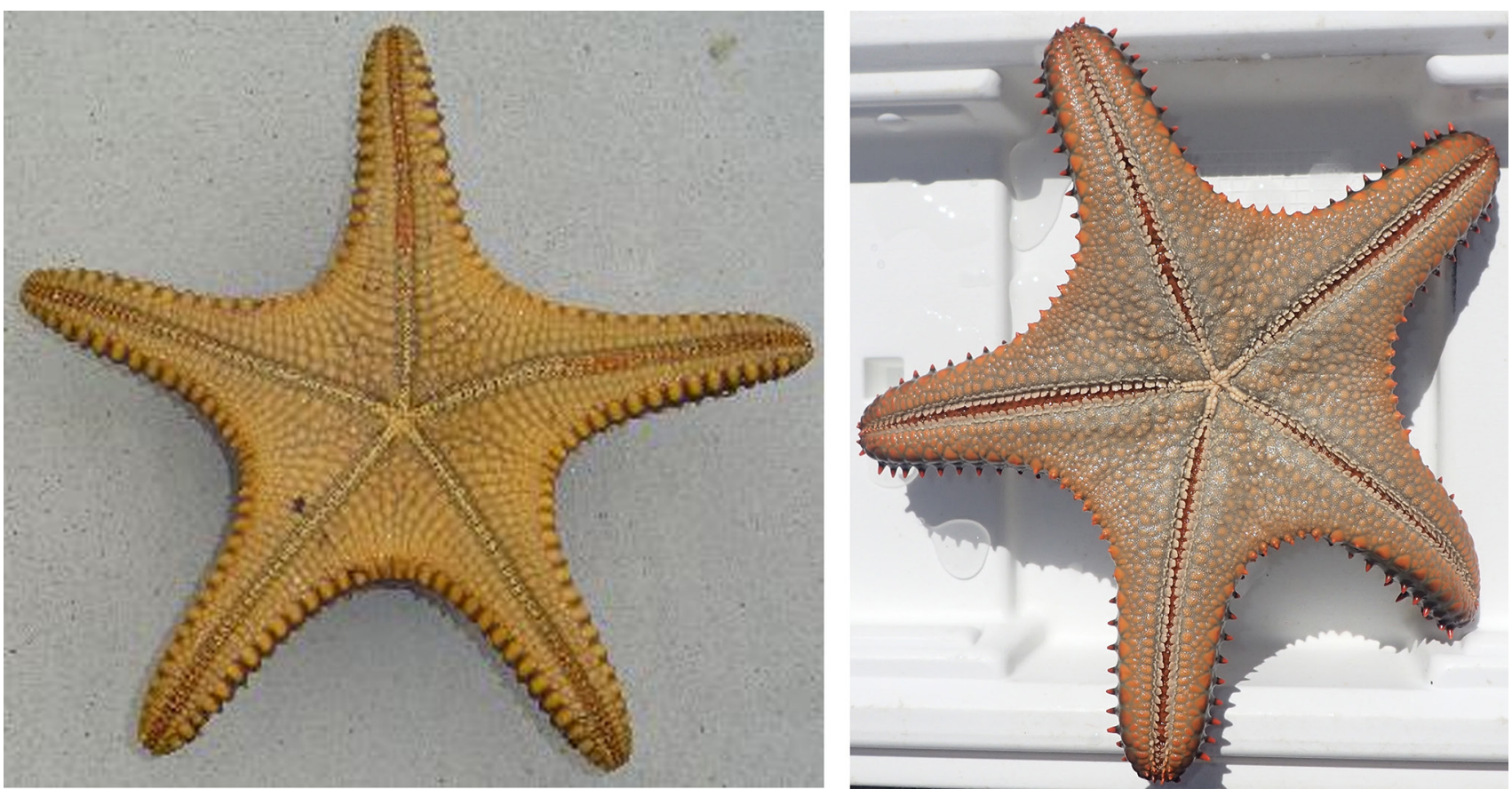

Figure 3. Live specimens of Pentaceraster regulus from Wallis Lake, actinal surface. Left specimen AM J.24502, right from AM J.27404.

23 Nov. 2020, by hand on snorkel; AM J.27403, 1 specimen (R $130 \mathrm{~mm}$ ), same data as AM J.27402; AM J.27404, 6 specimens (R 42, 70, 75, 78, 89, $123 \mathrm{~mm}$ ), Wallis Lake, New South Wales, Australia, 32 $11^{\prime} 4^{\prime \prime S} 152^{\circ} 30^{\prime} 41^{\prime \prime E}$, collected S.J. Keable \& C. Rowe, 9 Dec. 2020, by hand on snorkel, sand and seagrass beds, $1-4 \mathrm{~m}$.

\section{Identification}

A species possessing highly variable characters making species delimitation unclear. It should be noted that while identification of the species is made with confidence, the genus Pentaceraster has been recognized as problematic throughout its history (Doderlein, 1936; Clark \& Rowe, 1971).

Identification of this species is based on Doderlein's (1936) account which was applied to most of the individuals from the collection reported here (Figs 2-5, 7). These specimens were also distinguished following the work of Marsh \& Fromont (2020) who recognized the absence of superomarginal spines from the proximal-most interradial marginal plates, but having spines present on the remaining superomarginals and inferomarginals. There are few to no prominent spines from the adradial/dorsolateral regions along the arms, although small spines may be present. Adradial/dorsolateral plates of the disc and central plates are almost all with small spines. Carinal spines are weakly developed and similar in size/stature to spines elsewhere on the body surface.

Although the characters of these specimens seem broadly consistent with those of Doderlein (1936), there does appear to be significant variation if compared with individuals from other localities. For example, Jangoux (1986) reported this species from New Caledonia with larger and much more pronounced carinal and distalmost superomarginal spines, and a near complete absence of dorsolateral spines from either the disk or arms.

The individual registered as AM J.27403 (Figs 2, 5) differs from the other specimens in that it displays characters which conform to those used to diagnose Pentaceraster regulus sensu characters outlined by Clark \& Rowe (1971) rather than those of Doderlein (1936), including a full series of spines present throughout the interradial marginal plates, the presence of intermarginal plates interradially, and more abundant spines on the dorsolateral/adradial disk and arm regions which occur in regular series, which Clark in Clark \& Rowe (1971) attributes to size differences as part of a possible synonymy of $P$. regulus with $P$. gracilis (Lütken, 1871). A full assessment of that relationship is beyond the scope of this report, but it seems premature to conclude that these two species are synonyms. It should be noted that the four arms on this specimen are within the normal range for abnormal growth rather than damage from predation, since tube foot furrows are present for four arms rather than five (Fig. 5).

Minute character differences, including those noted above, might indicate additional species within Pentaceraster, which have not been previously evident. Therefore, further study, especially utilizing molecular techniques, may potentially show additional cryptic diversity.

\section{Colouration in life}

Marsh \& Fromont (2020) summarize the colour of live individuals as being variable, often grey with brown marginal plates and actinal surface. They also note populations from New Caledonia are a uniform dark red. Specimens from Wallis Lake are variable in colour (Figs 2, 3), with a grey abactinal surface and orange tubercles being most common but varying from the abactinal surface being completely orange with matching tubercles to black with orange tubercles (largest specimen AM J.27404) to cream with dark brown tubercles (AM J.27403). The actinal surface was generally grey with orange plates, with the plate colour dominating in some specimens.

\section{Ecological notes}

Marsh \& Fromont (2020) note this species occurs on sand and seagrass flats on coral reefs, mud, sand, shelly sand, or gravel. They also record it feeding on substrate biofilm of microorganisms and detritus, large Foraminifera and Bryozoa, and additionally preying upon heart urchins such as species of Breynia, Maretia, and Metalia. In Wallis Lake specimens were obtained from Breckenridge Channel adjacent to Miles (aka Sandy) and Leon Islands, c. 2.0-2.5 


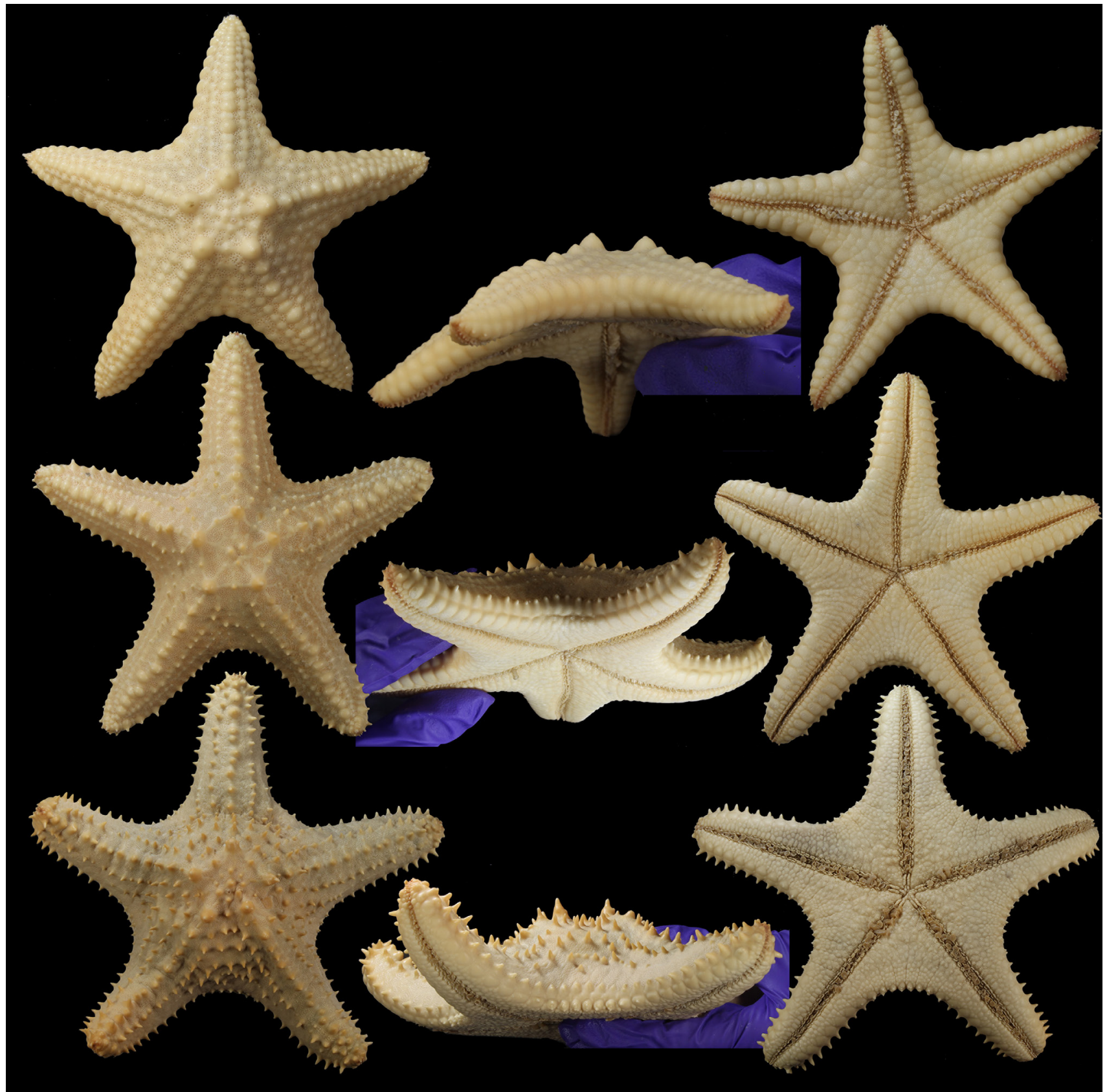

Figure 4. Preserved specimens of Pentaceraster regulus from Wallis Lake, AM J.27404, top row $\mathrm{R}=42 \mathrm{~mm}$, middle $\mathrm{R}=78 \mathrm{~mm}$, bottom $\mathrm{R}=123 \mathrm{~mm}$.

$\mathrm{km}$ from the entrance of the ocean to the lake (Fig. 1). This area is subject to relatively strong tidal currents, estuarine conditions are indicated by the presence of mangroves (Avicennia marina) and oyster leases adjacent to Miles and Leon Islands. The eastern shoreline of the channel in this vicinity is urbanized with a netted swimming enclosure, boathouse, marina, and boardwalk along the sandy shore adjoining the town of Forster but the shorelines of the islands to the west are relatively unmodified (Fig. 6). Within the channel, thick beds of Zostera seagrass, stabilizing silty sediments, dominate all but the central third to half of the channel which is predominately bare sand. Some patchy Halophila seagrass is also interspersed among the Zostera. The Zostera beds are somewhat sparse on the western bank along the southern half of Miles Island where the channel straightens. Water depth is less than $10 \mathrm{~m}$, with the deeper areas corresponding to those where the Zostera is absent, and the depths where Zostera is present generally being less than $4 \mathrm{~m}$. Specimens were found predominately among the Zostera (Fig. 7), with c. 12 scattered specimens being sighted in a two person straight line snorkel transect of $250 \mathrm{~m}$ along the eastern shore, in depths from c. 1.5-3.0 m. Whereas in a similar transect, along the relatively unvegetated area of the western shore adjacent to the southern half of Miles Island, only one specimen was observed but was fully exposed on sand (Fig. 7). The central area of the channel was not explored as intensively mainly due to boat traffic.

\section{Distribution}

The broad geographic range for Pentaceraster regulus is considered to be east Indo-west-central Pacific Ocean (Rowe \& Gates, 1995), encompassing India to Thailand, Indonesia, and the Philippines to northern Australia, New Caledonia, Fiji, and north to the Ryukyu Islands, Japan, in depths of 0-115 m (Marsh \& Fromont, 2020). Within Australia 


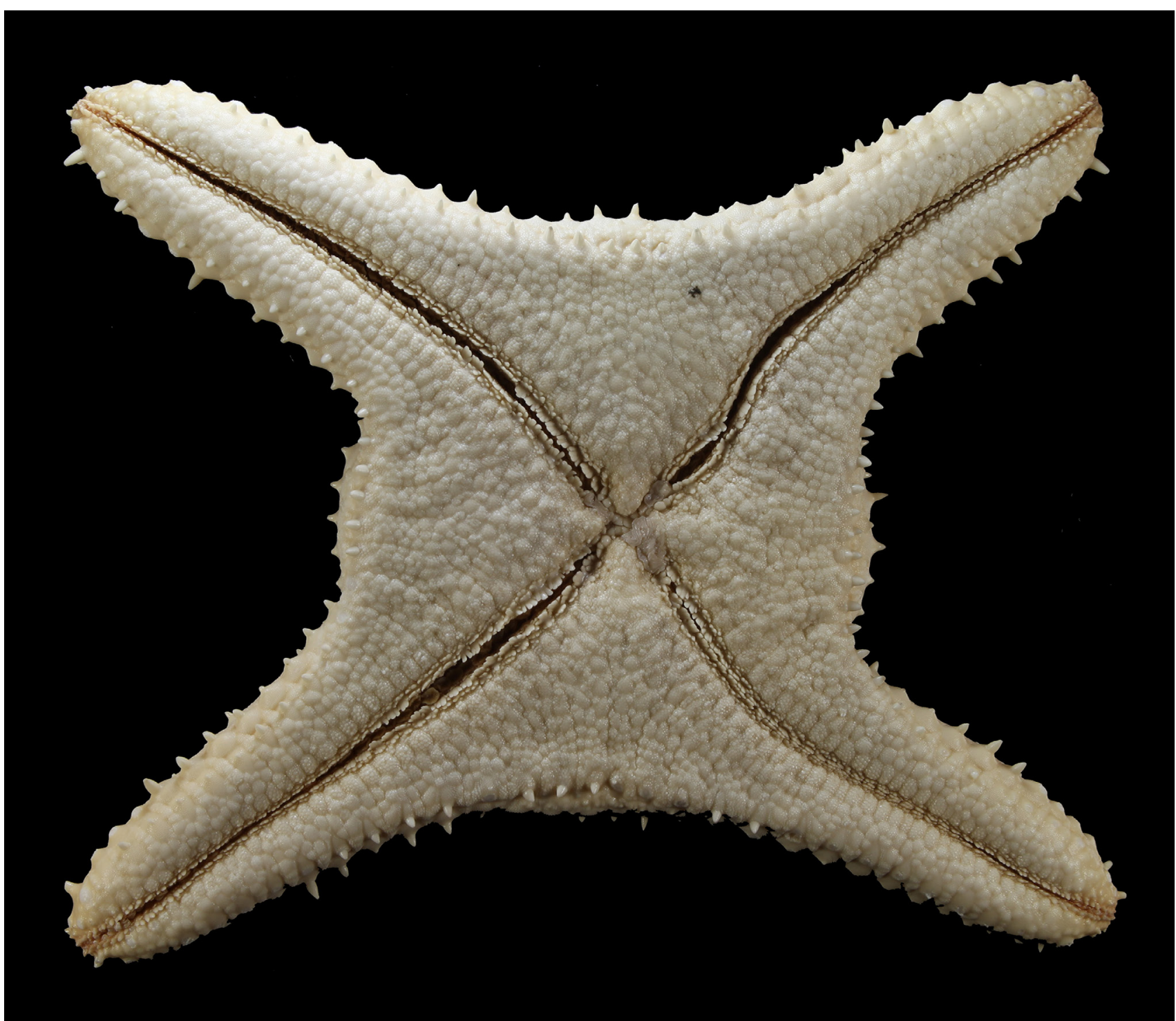

Figure 5. Preserved specimen of Pentaceraster regulus from Wallis Lake, AM J.27403, R = $130 \mathrm{~mm}$, actinal surface showing presence of only 4 spine furrows.

(Fig. 1) the distribution has previously been recorded from the Montebello Islands (c. $20^{\circ} 26^{\prime} \mathrm{S} 115^{\circ} 37^{\prime} \mathrm{E}$ ) and north western Australia including Ashmore Reef and the Timor Sea, through the Arafura Sea and Torres Strait, south along the east coast to near Double Island Point, Queensland, at a latitude and longitude of c. $26^{\circ} 17^{\prime} \mathrm{S} 153^{\circ} 24^{\prime} \mathrm{E}$ (Rowe \& Gates, 1995; Marsh \& Fromont, 2020; Atlas of Living Australia, 2021; AM registration E.1643). However, the Atlas of Living Australia (2021) has a record on the west coast, Western Australian Museum registration Z23152, Mandu Islands, Ningaloo Reef, Western Australia, 22 ${ }^{\circ} 10^{\prime} 09^{\prime \prime S} 113^{\circ} 50^{\prime} 17^{\prime \prime E}$. Additional records on the east coast south of this in coastal waters within $1 \mathrm{~km}$ of the mainland are Queensland Museum registration G.3715, from Dunwich (Stradbroke Island), Queensland, $27^{\circ} 30^{\prime} \mathrm{S} 153^{\circ} 24^{\prime} \mathrm{E}, 5.8 \mathrm{~m}$ and offshore AM J.19181, from Lord Howe Island lagoon, $31^{\circ} 32^{\prime} \mathrm{S} 159^{\circ} 04^{\prime} \mathrm{E}$. The specimens noted here from Wallis Lake (c. 32 ${ }^{\circ} 11^{\prime} 30^{\prime \prime} \mathrm{S}$ ) extend this distribution c. $640 \mathrm{~km}$ south from the Queensland records and are c. $600 \mathrm{~km}$ from Lord Howe Island although only about $85 \mathrm{~km}$ south from the equivalent mainland latitude and longitude to Lord Howe Island. Additionally, we are aware of citizen science reports of $P$. regulus occurring in the vicinity of Sydney (iNaturalist, 2021) which, if confirmed by additional records and taxonomic examination of specimens, would extend the distribution a further c. $240 \mathrm{~km}$ south.

\section{Remarks}

There are 14 currently accepted species of Pentaceraster (World Register of Marine Species, 2021) of which only four are known from Australian waters and only two, $P$. gracilis (Lütken, 1871) and P. regulus, are known from the mainland east coast (Rowe \& Gates, 1995; Marsh \& Fromont, 2020; Atlas of Living Australia, 2021). Neither $P$. gracilis nor $P$. regulus have been recorded from as far south as the records documented here from Wallis Lake for P. regulus.

Biogeography of Australian echinoderms has been summarized by O'Hara (2017), in an ordination analysis. This analysis divides up the east coast into five areas: NE coast, Central E coast, Lower E coast, Bass Strait, and Tasmanian Coast moving north to south respectively; it also considers Tasman Sea Islands including Lord Howe Island. In this analysis the NE coast and Tasman Sea Island faunas group together more closely with those found offshore within the Great Barrier Reef and are offset from that of the Lower East Coast into which records from Wallis Lake fit.

The special nature of the Lord Howe Island marine biota has been reviewed by Marine Parks Authority (2010). This area has long been recognized as the world's southernmost locality with a true coral reef community, and additionally has the only fringing coral reef lagoon this far south in Australian territorial waters. As such, the island provides 

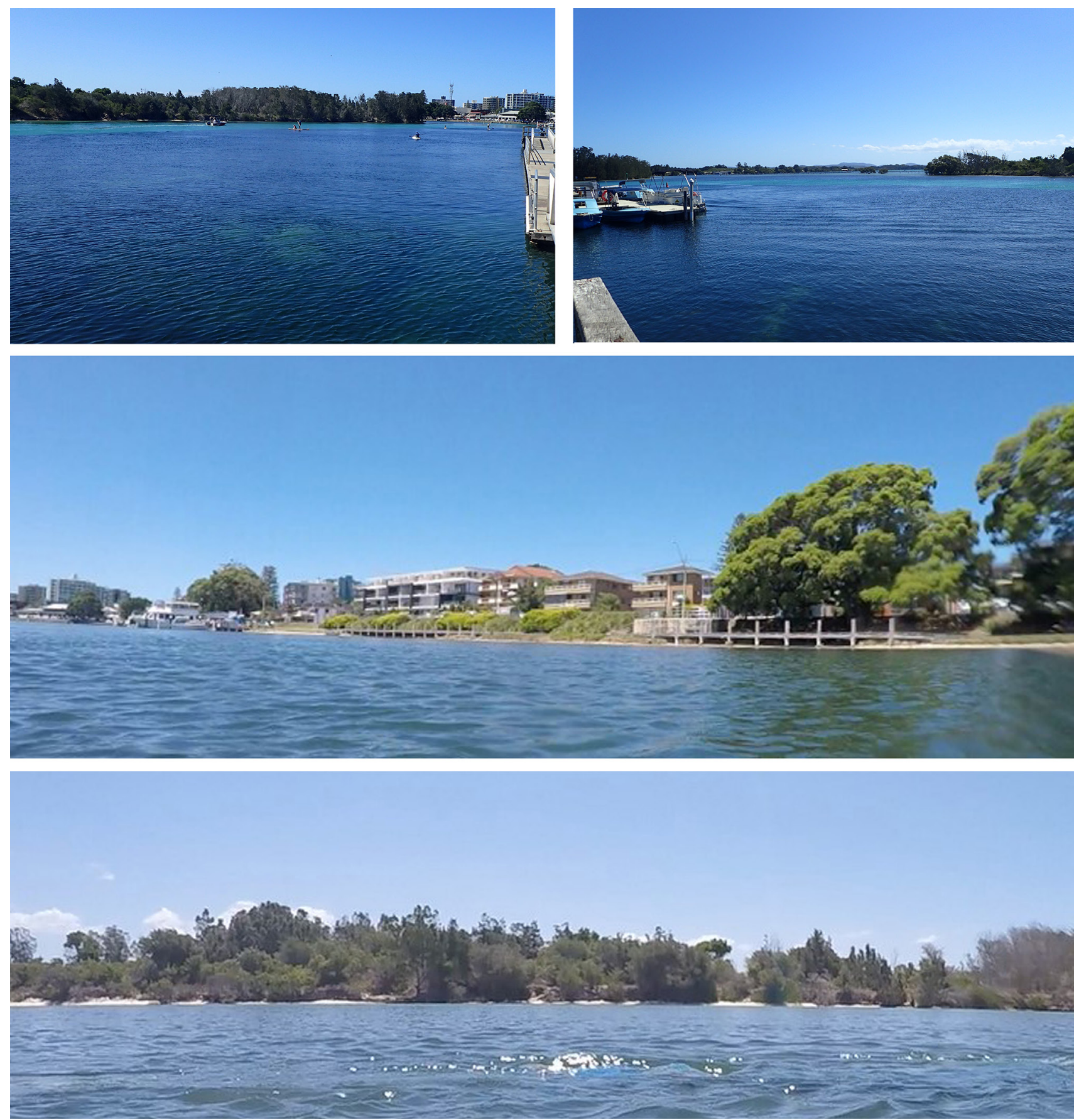

Figure 6. Breckenridge Channel, Wallis Lake, in the vicinity of the collection area for Pentaceraster regulus. From top left: from eastern shore looking north toward lake entrance and town of Forster; from eastern shore looking south toward main lake; from channel looking toward eastern shore; from channel looking west toward shore of Miles Island.

a significant example of the transition between coral and algal reefs and includes many species at their southern distributional limits, reflecting the extreme latitude of the Lord Howe Island coral reef ecosystem. However, many tropical species are common. The area is biogeographically significant because of the unusual combination of tropical species at their southernmost limits of distribution and subtropical species which are rare or absent from tropical reefs. The East Australian Current dominates ocean circulation around the island, flowing from the north along the eastern seaboard of the Australian continent before turning sharply south eastward away from the Australian coast into the Tasman Sea at c. $32^{\circ} \mathrm{S}$ (Roughan et al., 2011) in pulses during September to December before either returning north or dissipating. This explains why tropical taxa, such as corals, occur further south on Lord Howe Island than on the Australian mainland. Records of taxa with a typically northern tropical distribution, such as $P$. regulus, from the Lord Howe Island area are therefore not as unexpected as those reported here from the mainland at Wallis Lake which is within an area considered to be dominated by a temperate rather than tropical echinoderm fauna (O'Hara, 2017).

The environs of Wallis Lake have been reviewed in estuary and catchment management plans and ecological reports (Fiebig, 2010; Glasby \& van den Broek, 2010; Great Lakes Council, 2014). A knowledge gap recognized in these studies is the lack of information concerning macroinvertebrates within the estuary (Fiebig, 2010). Of the 55 species of macroinvertebrates known to occur only three echinoderms (unidentified Ophiuroidea) have been recorded 

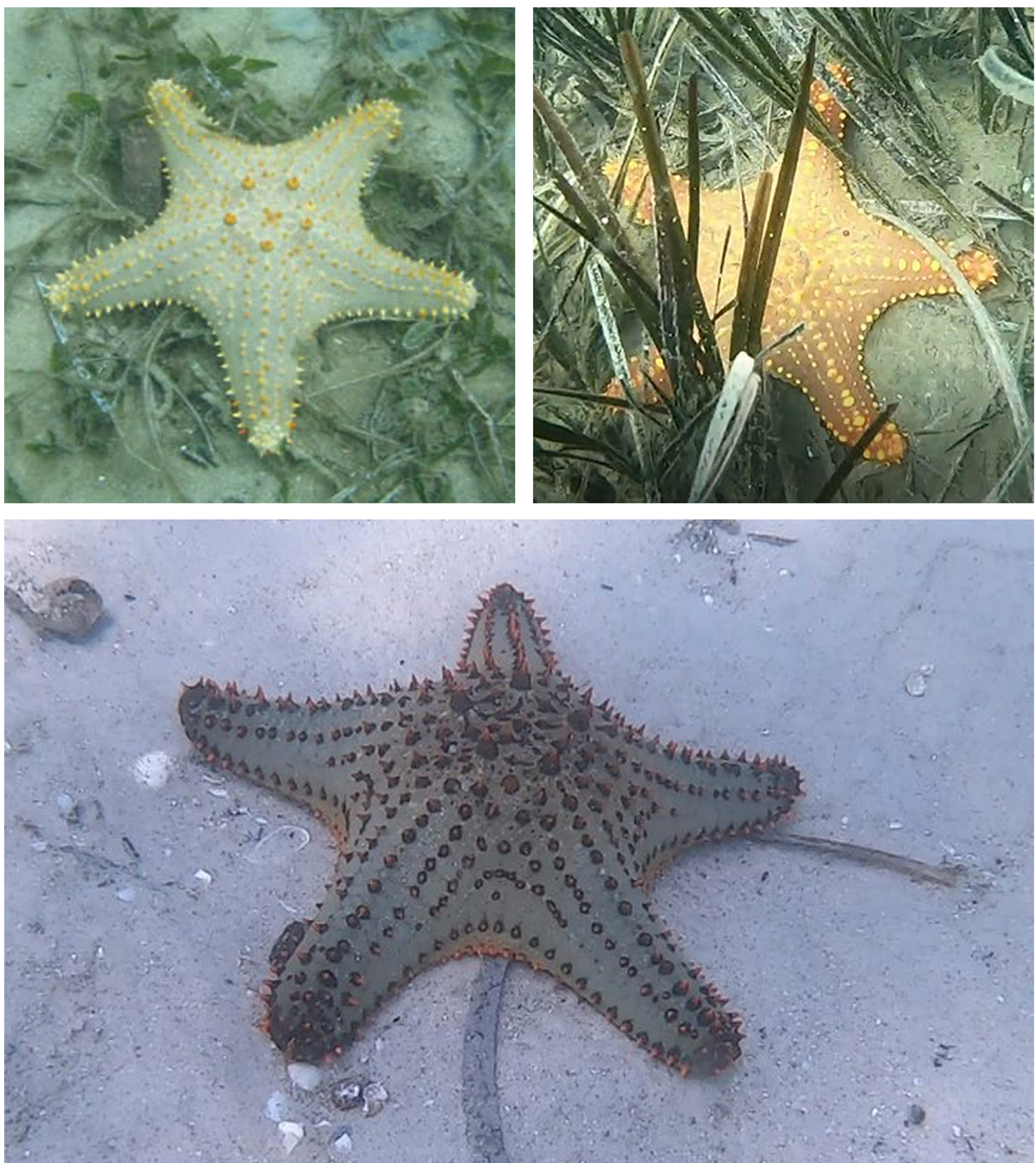

Figure 7. Live specimens of Pentaceraster regulus from Wallis Lake, showing substrate found on. Top left AM J.24503, top right specimen from AM J.27404, bottom largest specimen from AM J.27404.

(Glasby \& van den Broek, 2010; Fiebig, 2010). Without a sufficient baseline survey and comprehensive information to refer to, the evidence that the population of Pentaceraster regulus within Wallis Lake has been recently established is inferred from other supporting data.

In this context faunal repositories are particularly revealing in regard to long term temporal distributions. The collections of the Australian Museum are especially significant as they include specimens from the early review and study of Australian echinoderms, by authors such as Whitelegge and H. L. Clark in the late 1800s and early 1900s through to the present (see Rowe \& Gates (1995) for details), and it is the primary institution receiving echinoderms from New South Wales waters including Wallis Lake. Using data from these samples provides an important baseline to identify changes and long term trends. Currently this collection holds c. 2,679 registered lots of asteroids from 1,441 samples obtained from Queensland localities compared to 2,479 lots in 1,169 samples from New South Wales to the south (i.e. of the totals from the two states New South Wales comprises $48 \%$ of lots from $45 \%$ of the samples). Given the New South Wales coastline is substantially shorter than the east coast of Queensland (c. 1,090 linear km versus 2,250 km, i.e. c. $48 \%$ ) it is possible to contend that New South Wales has been 
more intensively sampled. Within the Queensland samples there are specimens of $P$. regulus included from 13 localities spanning the latitude range $10^{\circ} 41^{\prime} \mathrm{S}$ (Prince of Wales Island, Torres Strait) to $26^{\circ} 17^{\prime} \mathrm{S}$ (Double Island Point), including the vicinities of Nymph Island, Lizard Island, Cooktown, Port Denison, Langford Island, North West Islet, Wistari Reef, Mast Head Island, Port Curtis, Lady Elliot Island, and Tin Can Bay with collection dates from 1908 to 1979. Whereas the collections from New South Wales only have material from the two localities highlighted here, Lord Howe Island (collected in 1985) and Wallis Lake (collected in 2008 and again in 2020).

Additionally, it is notable that Pentaceraster regulus is a large and spectacular species, not readily overlooked and that the records reported here were drawn to our attention through members of the local Wallis Lake community. Their interest in the apparent arrival of the species locally led to their quest for identification and further information. The initial enquiry in 2008 indicated that only the two specimens recorded here were present (AM J.24502 and J.24503) and may have been associated with recreational vessels visiting the area from localities such as Lord Howe Island. However, the subsequent collections and field observations in 2020 show that a population is established with numerous individuals present and the size range recorded ( $\mathrm{R} 42$ to $130 \mathrm{~mm}$ ) suggests that most, if not all, of the lifecycle is taking place within Wallis Lake. Furthermore, species with an otherwise tropical distribution such as the upside-down jellyfish, Cassiopea sp. have also recently been recorded for the first time within the lake over a similar time scale (Keable \& Ahyong, 2016).

Given that available evidence suggests Pentaceraster regulus is more common to the north, has recently become established in Wallis Lake and is reproducing there, this may be another example of climate driven change pushing species ranges poleward and increasing tropicalization of New South Wales waters as evidenced by other taxa (Verges, 2014). Echinoderms, including asteroids such as Pentaceraster regulus are known to exert considerable influences on ecosystems. Significant examples in Australian waters include the echinoid Centrostephanus rodgersii, and the asteroids Acanthaster planci and Asterias amurensis (Byrne \& Andrew, 2013; O'Hara \& Byrne, 2017; Ling \& Keane, 2018). We therefore highlight the need for future ecological studies of the impact of $P$. regulus within Wallis Lake and other areas south of the historical records reviewed here to determine if any community interactions are occurring which may indicate significant ecosystem change resulting from the presence of this seastar.

\section{Conclusion}

Examination of specimens shows that Pentaceraster regulus is established within Wallis Lake, New South Wales extending the known mainland distribution of the species south by c. $640 \mathrm{~km}$. Review of historical collections suggests this is a recent range shift and may be evidence of further tropicalization of this part of the east Australian coast. It would be prudent to undertake ecological studies to determine the impact $P$. regulus may have in areas that such a range shift encompasses.
Acknowledgements. Ms Claire Rowe is thanked for field and technical support, including video from which images of live specimens from AM J.27404 were taken. Dr Laetitia Gunton is thanked for images of preserved specimens from AM J.27402, J.27403 and J.27404. Mr Michael Koukoulas (NSW Fisheries) and Ms Alanna Bowd are thanked for obtaining, photographing and preserving specimens in AM J.24502 and J.24503, and bringing the presence of Pentaceraster regulus in Wallis Lake to our attention in 2008. Mr Simon Patterson and students from Great Lakes College, Tuncurry, are thanked for collecting, photographing and preserving specimens in AM J.27402 and J.27403, and bringing the presence of Pentaceraster regulus in Wallis Lake to our attention in 2020. We thank Drs F. W. E. Rowe and T. D. O'Hara for constructive comments on an earlier version of the manuscript.

\section{References}

ABRS (Australian Biological Resources Study). 2021. Australian Faunal Directory. [Accessed 27 September 2021.] https://biodiversity.org.au/afd/home

Atlas of Living Australia. 2021. Pentaceraster regulus. [Accessed 27 September 2021.] https://www.ala.org.au/

Byrne, M., and N. L. Andrew. 2013. Centrostephanus rodgersii. In Sea Urchins: Biology and Ecology, ed. J. M. Lawrence, third edition, pp. 243-256. San Diego: Academic Press. https://doi.org/10.1016/B978-0-12-396491-5.00017-4

Clark, A. M., and F. W. E. Rowe. 1971. Monograph of Shallowwater Indo West Pacific Echinoderms. London: British Museum (Natural History).

Döderlein, L. 1916. Über die Gattung Oreaster und verwandte. Zoologische Jahrbücher 40: 409-440.

Döderlein, L. 1926. Über Asteriden aus dem Museum von Stockholm. Kongliga Svenska Vetenskaps-Academiens Handlingar 2(6): 3-22, pls 1-4.

Döderlein, L. 1936. Die Asteriden der Siboga Expedition. III. Die Unterfamilie Oreasterinae. Siboga-Expéditie Report 46(c): 295-369, pls 21-32.

Fiebig, S. 2010. Summary of Ecological Information for the Wallis Lake Potential RAMSAR Site (Final Draft Report), Pacific Blue Design, New South Wales. [Accessed 27 September 2021.]

Fisher, W. K. 1908. Necessary changes in the nomenclature of starfishes. Smithsonian Miscellaneous collections (Quarterly) 52: 87-93.

Flagor, T. E., and P. E. Bourdeau. 2018. First record of the predatory snail Acanthinucella spirata (Blainville, 1832) north of its known range. Marine Biodiversity Records 11(19): 1-6. https://doi.org/10.1186/s41200-018-0156-z

Glasby, T., and J. van den Broek. 2010. Macrophytes, Fishes and Invertebrates of Wallis Lake, New South Wales. Industry and Investment NSW, New South Wales. [Accessed 27 September 2021].

Great Lakes Council. 2014. Wallis Lake Estuary and Catchment Management Plan. Great Lakes Council, Forster. [Accessed 27 September 2021.]

iNaturalist. 2021. [Accessed 27 September 2021.] https://www.inaturalist.org/observations/26223766

Jangoux, M. 1986. Les asterides. In Guide des etoiles de mer, oursins et autres echinodermes du lagon de Nouvelle-Caledonie, ed. A. Guille, P. Laboute, and J. L. Menou. Faune Tropicale, Orstom, Paris, 25: 109-153.

Keable, S. J., and S. T. Ahyong. 2016. First Records of the invasive "Upside-down Jellyfish", Cassiopea (Cnidaria: Scyphozoa: Rhizostomeae: Cassiopeidae), from Coastal Lakes of New South Wales, Australia. Records of the Australian Museum 68(1): 23-30. 
Ling, S. D., and J. P. Keane. 2018. Resurvey of the Longspined Sea Urchin (Centrostephanus rodgersii) and Associated Barren Reef in Tasmania. Hobart: University of Tasmania, Institute for Marine and Antarctic Studies Report.

Lütken, C. F. 1871. Fortsatte kritiske og beskrivende Bidrag til Kundskab om Söstjernerne (Asteriderne). Videnskabelige Meddelelser fra Dansk Naturhistorisk Forening i Kjøbenhavn 23: 227-304.

Marine Parks Authority. 2010. Natural Values of Lord Howe Island Marine Park. Hurstville, Australia: NSW Marine Parks Authority.

Marsh, L. M., and J. Fromont. 2020. Field Guide to the Shallow Water Seastars of Australia. Welshpool: Western Australian Museum.

Müller, J., and F. H. Troschel. 1842. System der Asteriden. Braunschweig: Papier, Druck und Verlag.

O'Hara, T. D. 2017. Biogeography. In Australian Echinoderms Biology, Ecology and Evolution, ed. M. Byrne and T. D. O'Hara, pp. 137-153. Melbourne and Canberra: CSIRO Publishing and ABRS.

O’Hara, T. D., and M. Byrne. 2017. Management: Fisheries, Ferals and Conservation. In Australian Echinoderms Biology, Ecology and Evolution, ed. M. Byrne and T. D. O'Hara, pp. 95-135. Melbourne and Canberra: CSIRO Publishing and ABRS.
Roughan M., H. S. Macdonald, M. E. Baird, and T. M. Glasby. 2011. Modelling coastal connectivity in a Western Boundary Current: Seasonal and inter-annual variability. Deep-Sea Research II 58: $628-644$

https://doi.org/10.1016/j.dsr2.2010.06.004

Rowe, F. W. E, and J. Gates. 1995. Echinodermata. In Zoological Catalogue of Australia, volume 33, ed. A. Wells. Canberra: Australian Government Printing Service.

Vergés, A., P. D. Steinberg, M. E. Hay, A. G. B. Poore, A. H. Campbell, E. Ballesteros, K. L. Heck Jr, D. J. Booth, M. A. Coleman, D. A. Feary, W. Figueira, T. Langlois, E. M. Marzinelli, T. Mizerek, P. J. Mumby, Y. Nakamura, M. Roughan, E. van Sebille, A. Sen Gupta, D. A. Smale, F. Tomas, T. Wernberg, and S. K. Wilson. 2014. The tropicalization of temperate marine ecosystems: climate-mediated changes in herbivory and community phase shifts. Proceedings of the Royal Society B (Biological Sciences) 281(20140846): 1-10. https://doi.org/10.1098/rspb.2014.0846

World Register of Marine Species. 2021. [Accessed 27 September 2021.]

http://www.marinespecies.org/index.php 